\title{
Tecnología Biofloc (BFT), una alternativa sostenible para el desarrollo de la acuicultura: Una revisión
}

\section{Biofloc Technology (BFT), a sustainable alternative for the development of aquaculture: a review}

\author{
Fabián Guillermo Ariza ${ }^{[1]}$ y Edinson Mujica ${ }^{[]^{*}}$
}

Fecha de envío:

Fecha de Revisión:

Fecha de aceptación:

\section{Resumen}

Este artículo presenta una revisión sobre las principales características de la Tecnología Biofloc (BFT), los requerimientos para el buen funcionamiento del sistema y la clase de microorganismos que la componen. De igual manera, con este documento se busca promover la aplicación de tecnología dentro de las explotaciones acuícolas regionales, principalmente en la producción de tilapia, ya que es una alternativa sostenible y amigable con el medio ambiente.

Palabras clave: tratamiento de aguas; proteína de origen acuático; sostenibilidad; microorganismos.

\begin{abstract}
This article presents a review of the main features of the Biofloc (BFT) technology, the requirements for the proper functioning of the system and the type of microorganisms that compose it. Similarly, this document seeks to promote the application of technology within regional aquaculture farms, mainly in the production of tilapia, as it is sustainable and friendly alternative environment.
\end{abstract}

Keywords: water treatment; protein of aquatic origin; sustainability; microorganisms.

\footnotetext{
${ }^{[1]}$ Ingeniero Agrícola. Microfertisa S.A.S. fabianariza71@gmail.com

${ }^{[2]}$ MSc en Ingeniería Agrícola y Uso Integral del Agua. Docente Universidad Surcolombiana. edinsonagricola@gmail.com *(Autor para correspondencia)
} 


\section{Introducción}

La acuicultura es el sector productivo de alimentos de más rápido crecimiento en el mundo, en virtud de que es la única vía sostenible para acortar la brecha de la demanda de proteína de origen acuática (AUNAP, 2013). Éste enfoque global, supone que tanto las organizaciones como los productores deben realizar estrategias que impacten positivamente en su desarrollo. Por otra parte, el pescado y los productos pesqueros desempeñan un papel importante en la seguridad alimentaria y nutricional, la reducción de la pobreza y el bienestar general (FAO, 2014), lo que garantiza un ambiente competitivo y loable dentro de la acuicultura. En la actualidad, la comunidad mundial se enfrenta a retos relacionados con atender las necesidades apremiantes de alimentación y nutrición de una población creciente con recursos naturales finitos (FAO, 2012).

Es así, que la acuicultura se ha ido desarrollando de manera constante durante las últimas décadas para satisfacer la creciente demanda de productos pesqueros en el mercado mundial. Sin embargo, problemas ambientales como la liberación de efluentes de granjas y falta de tratamiento, la alta dependencia de harina de pescado para preparación de alimentos y el brote de enfermedades (Prajith, 2012), han limitado aún más la expansión de su industria (Wang, et al., 2015a). Por lo que resulta conveniente, diseñar nuevos modelos productivos con capacidad de ahorrar costos de energía, reducir la emisión de gases de efecto invernadero, reducir al mínimo la eliminación de desechos, y, aún más, para reciclar los nutrientes dentro del sistema (Munguia, et al., 2015).

Una alternativa para disminuir los daños ambientales como el exceso de nutrientes y materia orgánica ocasionados por la acuicultura y optimizar su producción, es el uso de la Tecnología Biofloc (BFT), la cual consiste en el desarrollo de flóculos microbianos, formados a partir de una relación Carbono/Nitrógeno (C:N) en el agua, con alta oxigenación (Emerenciano, et al., 2013a), intercambio de agua limitada o nula (Cardona, et al., 2015) centrado en el uso más eficiente de los nutrientes de entrada al sistema (Widanarni, et al., 2012). Esta tecnología aprovecha los residuos de los alimentos, materia orgánica y compuestos inorgánicos tóxicos, resolviendo así sustancialmente los problemas de saturación de nutrientes a partir de su reciclaje (Avnimelech, 2009; Collazos y Arias, 2015). Los científicos han descrito esta tecnología como una unidad autosostenible, capaz de purificar las aguas residuales de la acuicultura y fabricar alimento para peces simultáneamente (Ogello, et al., 2014).

Además, con el fin de cubrir la demanda actual de pescado, se ha implementado la BFT en la producción de tilapia, que es considerada uno de los peces con mayor futuro comercial, debido a su corto período de crecimiento y su alta adaptabilidad a los ambientes de producción (Vásquez, et al., 2014). Según Hargreaves (2013) la tilapia posee adaptaciones fisiológicas que le permiten consumir Biofloc y digerir proteína microbiana.

El objetivo de este documento es revisar las principales características de la Tecnología Biofloc, así como la aplicabilidad de ésta en la acuicultura, principalmente en el cultivo de tilapia y, describir su utilización y manejo dentro de un sistema de producción intensiva, desde una perspectiva sostenible $\mathrm{y}$ amigable con los recursos naturales.

\section{Revisión de la literatura}

La BFT es una tecnología utilizada en el tratamiento de aguas, considerada un enfoque para reducir costos de alimentación y problemas ambientales asociados con la descarga de productos de desecho (Liu, et al., 2014), ofreciendo la posibilidad de mantener una buena calidad del agua en los sistemas de acuicultura (Zhao, et al., 2012). Tiene varias funciones importantes: amplificar la productividad natural, mejorar la viabilidad de cultivo mediante la nutrición y; reducir la tasa de conversión alimenticia y los costos de alimentación (Ray, 2012). Es también, una técnica económica, robusta y de fácil operación (Crab, et al., 2012), que estimula el proceso 
de asimilación de nitrógeno inorgánico por bacterias heterótrofas para convertir los nutrientes de los lodos de la acuicultura en biomasa bacteriana (De Schryver, 2009). Estas bacterias utilizan amonio, además de los desechos nitrogenados orgánicos, para sintetizar nuevas células, utilizando simultáneamente materia orgánica, microorganismos y algunos sólidos en suspensión para así formar los flóculos (Hargreaves, 2006).

Asimismo, es una opción para el desarrollo de prácticas sostenibles en la acuicultura (Pérez, et al., 2013), se considera un sistema alternativo eficaz, donde los nutrientes pueden ser reciclados y reutilizados de forma continua (Bakar, et al., 2014). Aporta beneficios a los sistemas de producción, como disminución de la densidad de contaminantes tóxicos que pueden afectar los cultivos; disminuye o elimina la necesidad de recambios periódicos en los estanques, que es de gran ayuda cuando se presenta escasez de recursos hídricos; es un auxiliar para evitar la contaminación de cuerpos de agua, ya que mejora las condiciones de sanidad en los estanques ya que las bacterias heterótrofas inhiben el crecimiento de organismos patógenos, lo que reduce la posibilidad de que éstos parasiten los organismos en cultivo, previniendo contagios y muertes masivas (Castro, et al., 2012). Este tipo de tecnología es de gran apoyo para la acuicultura, rentable y ambientalmente sostenible (Ahsan, et al., 2014).

A diferencia de muchos sistemas de recirculación, la BFT no se basa en la filtración biológica externa, sino más bien en una comunidad microbiana densa que se desarrolla en la columna de agua (Ray, 2014), para ayudar en la eliminación de amoniaco a través de la absorción de fitoplancton y bacterias (Schrader, et al. 2011). Además, fue considerada recientemente como una técnica más ecológica y sostenible para su uso en sistemas de cultivo de cero recambios de agua (Long, et al., 2015), puesto que ha demostrado ser una alternativa eficaz para convertir los nutrientes sin digerir de los residuos de alimentos y residuos fecales, en biomasa de bacterias heterótrofas (Liang, et al., 2014).

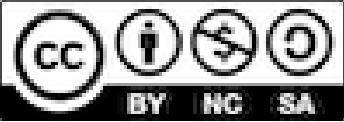

En comparación con las tecnologías convencionales de tratamiento de aguas usadas en la acuicultura, la BFT ofrece una alternativa más económica (disminución de los gastos de tratamiento de agua en el orden del 30\%), y adicionalmente, una ganancia potencial en los gastos de alimentación, lo que es un componente de bajo costo sostenible para el desarrollo futuro de la acuicultura (Avnimelech, 2009).

\subsection{Características y requerimientos del sistema Biofloc}

Para el diseño y gestión de los sistemas Biofloc, se debe tener en cuenta: el inductor Biofloc (cepas de bacterias y/o materiales orgánicos); la relación $\mathrm{C}: \mathrm{N}$ y la carga orgánica total; la fuente de carbono orgánico; la relación de intercambio de agua (mínimo o cero) y la intensidad de la mezcla en la columna de agua; la luz (intensidad y tiempo de exposición); los sólidos suspendidos totales y algunas variables ambientales (temperatura, salinidad, oxígeno disuelto y $\mathrm{pH}$ ) (Martínez, et al., 2014). De esta amplia gama de factores depende la duración de la puesta en marcha de un sistema acuícola (Hargreaves, 2013). La calidad del agua y una concentración adecuada de oxígeno indican que la biomasa de peces puede ser fácilmente criada por el enfoque de la BFT (Crab, et al., 2009).

Aparte de ser una fuente de proteínas de calidad, la BFT posee agentes estimuladores de crecimiento y compuestos bioactivos (Ju et al., 2008a), como los carotenoides, clorofilas, polisacáridos, fitosteroles, taurina, vitaminas liposolubles (Ju, et al., 2008 $\mathrm{a}$ 2008b), lípidos, fosfolípidos y ácidos grasos (Cardona, et al., 2016) disponibles "in situ" 24 horas por día (Avnimelech, 2007), por lo cual, es considerado fuente importante de alimento natural (Monroy, et al., 2013).

Alrededor del 20 al $30 \%$ del Nitrógeno añadido en la alimentación es asimilado por los peces, lo que implica que el 70 a $80 \%$ se libera al medio de cultivo como residuos (Hargreaves, 2013). Los sistemas Biofloc tienen tres vías para la conversión del Nitrógeno: captación fotoautotrófica por algas, 
conversión bacteriana quimioautotrófica de Amoníaco y Nitrógeno a Nitratos, y la asimilación de bacterias heterótrofas de amoníaco y nitrógeno directamente a la biomasa bacteriana (Ebeling, et al., 2006). Según Avnimelech (2009) a diferencia de las técnicas convencionales, tales como los biofiltros, la BFT soporta la eliminación de Nitrógeno incluso cuando la materia orgánica y la Demanda Biológica de Oxígeno (DBO) del agua del sistema es alta.

Los sistemas Biofloc normalmente funcionan con concentraciones de Sólidos Suspendidos (SS) de menos de $1000 \mathrm{mg} / \mathrm{L}$, y es más frecuente un valor menor de $500 \mathrm{mg} / \mathrm{L}$. Mantener una concentración de solidos sedimentables de 25 a $50 \mathrm{ml} / \mathrm{L}$, proporcionará una buena funcionalidad en los sistemas utilizados para criar tilapia (Hargreaves, 2013). Las concentraciones de sólidos excesivas pueden obstruir las branquias de los peces, afectando su crecimiento y bienestar (Luo, et al., 2014). Para prevenir la sedimentación excesiva de partículas cerca del drenaje central, es recomendable colocar un aireador para volver a suspender las partículas cerca del centro de estanque (Avnimelech, 2011).

La alta concentración de Oxígeno Disuelto (OD) se mantiene por aireación continua (Green, 2015), que también mantiene el Biofloc en suspensión en la columna de agua (Ray, 2012). Según Hargreaves (2013), mientras exista suficiente mezcla y aireación para mantener un floc activo en suspensión, la calidad del agua puede ser controlada. Es absolutamente fundamental proporcionar suficiente aireación $\mathrm{u}$ oxigenación para satisfacer la alta demanda de oxígeno y para mantener la concentración en niveles seguros. Estas altas tasas de respiración, también indican que el tiempo de respuesta en caso de un fallo del sistema es muy corto, a menudo menos de una (1) hora. Por lo tanto, elementos de monitoreo, alarmas y sistemas de energía de emergencia son necesarios (Hargreaves, 2013). La elección del sistema de aireación es crucial para obtener una alta productividad en el sistema, El rango de aireación requerida es de 7,5 a $15 \mathrm{Kw}$ para un estanque de 0,1 ha (Avnimelech, 2011). Los blower (sistemas de difusión de aire) son más eficientes en la agregación de las partículas y en la formación de Biofloc en cultivo (Lara, et al., 2016).

Por otro lado, se requiere cerca de 20 unidades de Carbono para asimilar una unidad de Nitrógeno, esto se logra adicionando alimento de baja proteína y un carbohidrato como por ejemplo la melaza, en cantidad suficiente (Emerenciano, et al., 2011b). La manipulación de la relación $\mathrm{C}: \mathrm{N}$ para el desarrollo de Biofloc ha mostrado ser prometedor en la acuicultura (De Lorenzo, et al., 2016; Anand, et al., 2013). En tanto, la alcalinidad debe mantenerse entre 100 y 150 $\mathrm{mg} / \mathrm{L}$ al agregar periódicamente bicarbonato de calcio (Hargreaves, 2013); y, el volumen del Biofloc debe estar en el rango de 5 a $50 \mathrm{ml} / \mathrm{L}$ (Avnimelech, 2011).

\subsection{Composición microbiana del Biofloc}

Desde una perspectiva general, se considera como microorganismos a todos aquellos organismos que no pueden ser detectados a simple vista. Son componentes muy importantes de los ecosistemas acuáticos; viven en el sedimento, en la columna de agua y en función de la carga de nutrientes (Martínez, et al., 2014). Los microorganismos tienen un papel importante en el cultivo en estanques, en particular con respecto a la productividad, el ciclo de nutrientes, la nutrición de los animales cultivados, la calidad del agua, el control de enfermedades y el impacto ambiental de los efluentes. Las partículas de materia orgánica y otros organismos en la cadena trófica microbiana se han propuesto como posibles fuentes de alimento para animales acuáticos (Moriarty, 1997).

La biodiversidad de especies que se alojan en los flóculos depende del microbiota que se encuentra en el cuerpo de agua, algunas de ellas pueden funcionar como control biológico para especies patógenas mediante la exclusión competitiva o porque tienen propiedades probióticas (Wu, et al., 2012; Ray et al., 2010). Ésta microbiota asociada con Biofloc es capaz de eliminar compuestos tóxicos y reciclar nutrientes (Audelo, et al., 2012). 
Para Chu \& Lee (2004) el término Biofloc se aplica a un compuesto constituido por un 60 a $70 \%$ de materia orgánica, la cual incluye una mezcla heterogénea de microorganismos (Figura 1) y de 30 a $40 \%$ de materia inorgánica como coloides, polímeros orgánicos, cationes y células muertas. Pueden alcanzar un tamaño de hasta $1000 \mu \mathrm{m}$, son de forma irregular, altamente porosos y permeables a los fluidos. Estas comunidades microbianas se forman mediante la adición de carbono orgánico a un cuerpo de agua (Wang, et al., 2015b) y su capacidad para controlar la calidad de ésta en el sistema de cultivo y las propiedades nutricionales de los flóculos están influenciadas por el tipo de fuente de carbono utilizado (Crab, 2010).

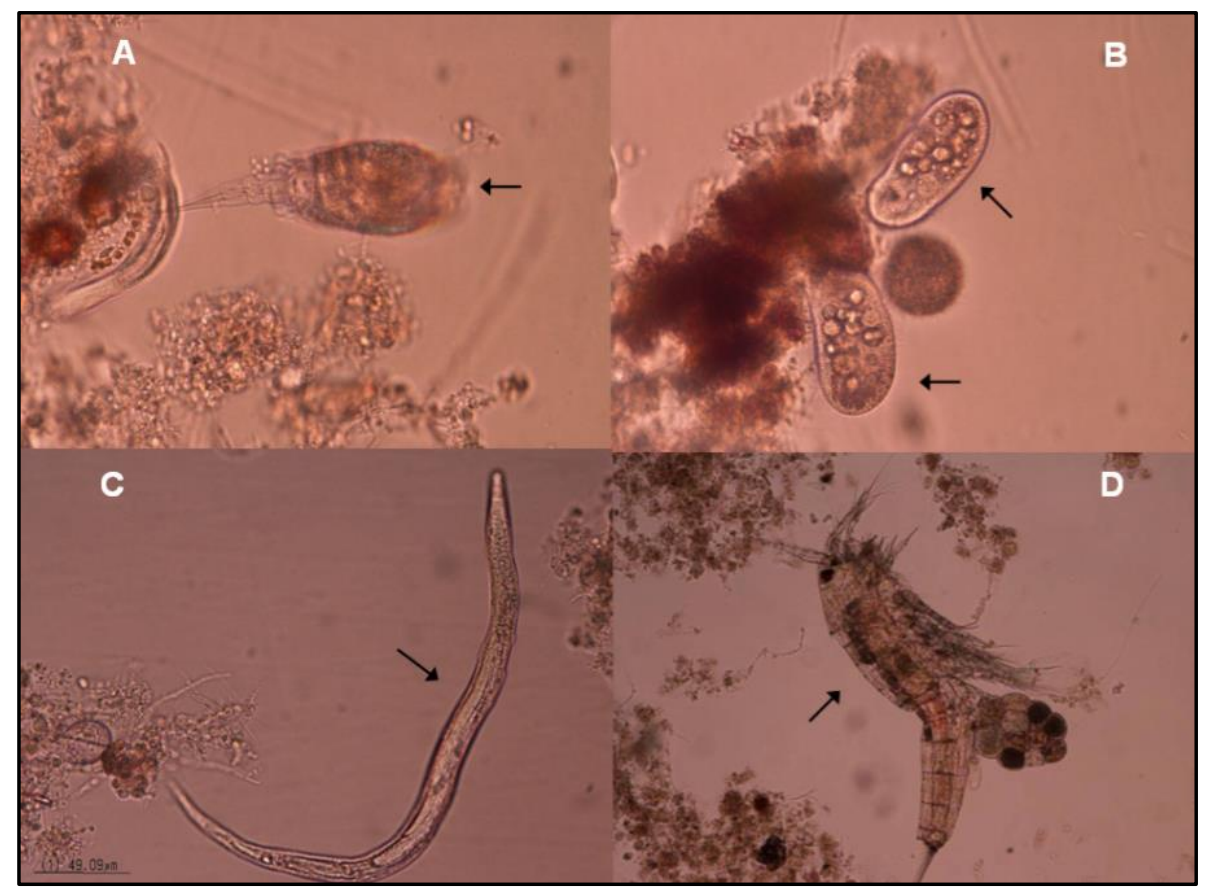

Figura 1. Herbívoros observados en BFT como protozoos flagelados (A), protozoos ciliados (B), nemátodos $(\mathrm{C})$ y copépodos (D) (aumento de 10x) (Emerenciano, et al., 2013b).

Muchos materiales prácticos y procesados se han utilizado como fuentes de carbono en los sistemas de Biofloc, incluyendo pellets de cereal, melaza, bagazo de caña, y pasto picado, entre otros (Hargreaves, 2013). Algunos investigadores sugieren que el azúcar y melaza se asimilan más rápidamente por las bacterias, aumentando la producción de Biofloc en menos tiempo (Avnimelech, 2013).

La sacarosa está fácilmente disponible en el mercado, debido a su uso en productos alimenticios, se disuelve rápidamente en agua y se ha demostrado con éxito que facilita la asimilación bacteriana de Nitrógeno (Ray, et al., 2011). En tanto, Emerenciano y colaboradores (2011b) sugiere la melaza, subproducto del proceso de fabricación de sacarosa como fuente adecuada de Carbono, ya que es menos costosa y favorece el crecimiento y la producción de bacterias heterótrofas (Xu, et al., 2016). Para promover el control heterotrófico de la concentración de amoníaco, las adiciones de carbohidratos deben ser hechas de acuerdo con la tasa de alimentación. Para cada $1 \mathrm{~kg}$ de alimentación de proteína de 30 a $38 \%$ añadido, se debe agregar de 0,5 a $1 \mathrm{~kg}$ de una fuente de carbohidratos (Hargreaves, 2013). Las bacterias heterótrofas obtienen carbono a partir de fuentes orgánicas y lo utilizan como fuente de energía; 
además, asimilan el Nitrógeno para construir las proteínas celulares (De Schryver, et al., 2008).

\subsection{Implementación de la Tecnología Biofloc en el cultivo de Tilapia}

La tilapia es una especie que, en la acuicultura se está produciendo intensamente (Ekasari, et al., 2015). Es un animal bentónico, que se cultiva debido a su facilidad de reproducción, tolerancia a una amplia gama de condiciones ambientales, adaptación al medio ambiente y resistencia a enfermedades (Liu, et al., 2014). Según Azim \& Little (2008), la calidad nutricional del Biofloc es apropiado para la tilapia, lo cual contribuye claramente a su crecimiento y producción.

La mayor parte de producción acuícola mundial se cría en sistemas semi intensivos y extensivos. Hoy en día, el interés en los sistemas de acuicultura intensiva de alta tecnología aumenta con la creciente demanda de productos (Rahman, et al., 2008). Widanarni y colaboradores (2012), sostiene que la aplicación de la BFT en el cultivo de tilapia puede mejorar la calidad del agua y la supervivencia de peces, así como reducir el requerimiento de alimentación externa. En los últimos tiempos, la BFT ha sido objeto de atención para el cultivo de tilapia porque promueve la alta producción, control de calidad del agua y reciclaje de alimentación de forma simultánea en la misma unidad (Little, et al., 2008). Es evidente que, con el crecimiento de la población humana, se necesita un progreso tecnológico en la acuicultura (Jiang, 2010), que sea sostenible y respetuoso con el medio ambiente (Widanarni, et al., 2012).

Un objetivo importante de gestión de calidad del agua en cualquier sistema de producción de animales acuáticos es el mantenimiento de la concentración de Amoníaco debajo de los niveles tóxicos (Hargreaves, 2013), debido a que el Nitrógeno inorgánico es el producto final del metabolismo de las proteínas y uno de los principales residuos en el agua (Liu, et al., 2016). La meta de la BFT en aplicaciones acuícolas es quitar y recuperar el Nitrógeno (Luo et al., 2013). Por consiguiente, si el agua descargada de una unidad acuícola es liberada sin ningún tratamiento adicional, puede no sólo perjudicar a la fauna acuática, sino también contribuir a la eutrofización de las aguas circundantes (Widanarni, et al., 2012). Por lo tanto, la reducción de intercambio de agua es una estrategia obvia para mejorar la bioseguridad agrícola (Hargreaves, 2013).

El reciclado de alimentos y la reducción al mínimo de intercambio de agua son importantes contribuciones a la economía de la producción de tilapia (Avnimelech, 2011), la BFT mejora la actividad de la enzima digestiva de la tilapia, favoreciendo el crecimiento y la utilización de alimento (Long, et al., 2015). Alrededor del $50 \%$ del gasto para la producción acuícola se derivan de los costos de alimentación, que es predominante debido al costo del componente de proteína en las dietas comerciales (Nahar, et al., 2015). Según Hargreaves (2013), del 20 al 30\% del crecimiento de la tilapia se debe al consumo y a la digestión de proteína microbiana. Este beneficio se refleja en una mejora de la conversión del alimento, uno de los mejores indicadores de rentabilidad del sistema y la sostenibilidad del negocio.

\section{Conclusiones}

La BFT permitirá que la acuicultura crezca hacia un enfoque respetuoso con el medio ambiente, trayendo consigo, una ventaja al minimizar el consumo y emisión de agua, el reciclaje de nutrientes y de materia orgánica (Emerenciano, et al., 2011a).

La forma más viable y ambientalmente aceptable para aumentar la producción de la acuicultura es mediante el uso de sistemas de producción intensiva; es así, como la BFT sirve como alternativa en la agricultura estándar, mediante la reducción del impacto ambiental. Ésta tecnología contribuirá enormemente a la producción acuícola, simplemente aprovechando el poder de la naturaleza (Yong, 2014).

Una limitante, que según Hargreaves (2013) mientras exista suficiente mezcla y aireación para mantener un floc activo en suspensión, la calidad del agua puede ser 
controlada. Es absolutamente fundamental proporcionar suficiente aireación u oxigenación para satisfacer la alta demanda de oxígeno y para mantener la concentración en niveles seguros.

\section{Referencias bibliográficas}

AUNAP, 2013. Diagnóstico del Estado de la Acuicultura en Colombia, Ministerio de Agricultura y Desarrollo Rural, Bogotá, 163 pp.

Ahsan, E., Rajib, S., Alam, M., Siddik, M., \& Nahar, A., 2014. Effects of Addition of Tilapia and Periphyton Substrates on Water Quality and Abundance of Plankton in Freshwater Prawn Culture Ponds. International Journal of Scientific \& Tecnology Research, 272-278.

Anand, S., Kumar, S., Panigrahi, A., Ghoshal, T., Dayal, S., Biswas, G., Sundaray, J., De, D., Raja, A., Deo, A., Pillai, S., \& Ravichandran, P., 2013. Effects of C:N Ratio and Substrate Integration on Periphyton Biomass, Microbial Dynamics and Growth of Penaeus Monodon Juveniles. Aquaculture International, 511524.

Audelo, J., Martinez, L., Gómez, S., \& Voltolina, D., 2012. Intensive Culture of Litopenaeus vannamei without Water Exchange and with an Artificial Substrate. Hidrobiológica , 1-7.

Avnimelech, Y., 2013. Biofloc Production Systems for Aquaculture. Southern regional aquaculture center, SRAC (4503), 1-11.

Avnimelech, Y., 2011. Tilapia Production Using Biofloc Technology Saving Water, Waste Recycling Improves Economics. Global aquaculture advocate May/June, 66-68.

Avnimelech, Y., 2009. Biofloc Technology - A practical Guide Book, The World Aquaculture Society, Israel, $182 \mathrm{pp}$.
Avnimelech, Y., 2007. Feeding with Microbial Flocs by Tilapia in Minimal Discharge Bioflocs Technology Ponds. Aquaculture, 140-147.

Azim, M., \& Little, D., 2008. The Biofloc Technology (BFT) in Indoor Tanks: Water Quality, Biofloc Composition, and Growth and Welfare of Nile Tilapia (Oreochromis niloticus). Aquaculture, 29-35.

Bakar, M., Nahar, A., Rahman, M., Anh, N., Nevejan, N., \& Bossier, P., 2014. Gut Weed, Enteromorpha sp. As a Partial Replacement for Commercial Feed in Nile Tilapia (Oreochromis niloticus) Culture. World Journal of Fish and Marine Sciences, 267-274.

Cardona, E., Lorgeoux, B., Chim, L., Goguenheim, J., Le Delliou, H., \& Cahu, C., 2016. Biofloc Contribution to Antioxidant Defence Status, Lipid Nutrition and Reproductive Performance of Broodstock of the Shrimp Litopenaeus stylirostris: Consequences for the Quality of Eggs and Larvae. Aquaculture, 252-262.

Cardona, E., Saulnier, D., Lorgeoux, B., Chim, L., \& Gueguen, Y., 2015. Rearing Effect of Biofloc on Antioxidant and Antimicrobial Transcriptional Response in Litopenaeus stylirostris Shrimp Facing an Experimental Sub-lethal Hydrogen Peroxide Stress. Fish \& Shellfish Immunology, 933-939.

Castro, L., Castro, T., De Lara, R., Castro, J., \& Castro, G., 2012. Sistemas Biofloc: un Avance Tecnológico en Acuicultura. Revista Digital del Departamento El Hombre y su Ambiente, 1-6.

Chu, C., \& Lee, D., 2004. Multiscale Structures of Biological Flocs. Chemical Engineering Science, 1875-1883.

Collazos, L., \& Arias, J., 2015. Fundamentos de la Tecnología Biofloc (BFT). Una Alternativa para la Piscicultura en Colombia. Una revisión. Orinoquía, 77-86. 
Crab, R., 2010. Bioflocs Technology: an Integrated System for the Removal of Nutrients and Simultaneous Production of Feed in Aquaculture, Ghent University, Faculty of Bioscience Engineering, Belgium, 196 pp.

Crab, R., Defoirdt, T., Bossier, P., \& Verstraete, W., 2012. Biofloc Technology in Aquaculture: Beneficial Effects and Future Challenges. Aquaculture, 351-356.

Crab, R., Kochva, M., Verstraete, W., \& Avnimelech, Y., 2009. Bioflocs Technology Application in Overwintering of Tilapia. Aquacultural Engineering, 105112.

De Lorenzo, M., Souza, E., Dias, D., Costa, P., Quadros, W., \& Do Nascimento, F., 2016. Intensive Hatchery Performance of Pacific White Shrimp in the Biofloc System Under Three Different Fertilization Levels. Aquacultural Engineering, 40-44.

De Schryver, P., \& Verstraete, W., 2009. Nitrogen Removal from Aquaculture Pond Water by Heterotrophic Nitrogen Assimilation in Lab-scale Sequencing Batch Reactors. Bioresource Technology, 1162-1167.

De Schryver, P., Crab, R., Defoirdt, T., Boon, N., \& Verstraete, W., 2008. The Basics of Bioflocs Technology: The added value for aquaculture. Aquaculture, 125-137.

Ebeling, J., Timmons, M., \& Bisogni, J., 2006. Engineering Analysis of the Stoichiometry of Photoautotrophic, Autotrophic, and Heterotrophic Removal of Ammonia-Nitrogen in Aquaculture Systems. Aquaculture, 346-358.

Ekasari, J., Rivandi, D., Firdausi, A., Surawidjaja, E. H., Zairin Jr., M., Bossier, P., \& De Schryver, P., 2015. Biofloc Technology Positively Affects Nile Tilapia (Oreochromis niloticus) Larvae Performance. Aquaculture, 72-77.
Emerenciano, M., Ballester, E., Cavalli, R., \& Wasielesky, W., 2011a. Effect of Biofloc Technology (BFT) on the Early Postlarval Stage of Pink Shrimp Farfantepenaeus Paulensis: Growth Performance, Floc Composition and Salinity Stress Tolerance. Aquacult Int, 891-901.

Emerenciano, M., Cupertino, E., Cavalli, R., \& Wasielesky, W., 2011b. Biofloc Technology Application as a Food Source in a Limited Water Exchange Nursery System for Pink Shrimp Farfantepenaeus brasiliensis (Latreille, 1817). Aquaculture Research, 447-457.

Emerenciano, M., Yves, G., Arévalo, M., \& Gabriela, G., 2013a. Biofloc Technology in Intensive Broodstock Farming of the Pink Shrimp Farfantepenaeus Duorarum: Spawning Performance, Biochemical Composition and Fatty Acid Profile of Eggs. Aquaculture Research, 1-33.

Emerenciano, M., Gaxiola, G., \& Cuzon, G., $2013 b$. Biofloc Technology (BFT): A Review for Aquaculture Application and Animal Food Industry, Biomass Now-cultivation and Utilization. InTech. 301-328.

FAO, 2014. El Estado Mundial de la Pesca y la Acuicultura, Oportunidades y Desafíos, Organización de las Naciones Unidas para la Alimentación y la Agricultura, Roma, 274 pp.

FAO, 2012. El Estado Mundial de la Pesca y la Acuicultura, Organización de las Naciones Unidas para la Alimentación y la Agricultura, Roma, 251 pp.

Green, B., 2015. Performance of a Temperate-zone Channel Catfish Biofloc Technology Production System During Winter. Aquacultural Engineering, 6067.

Hargreaves, J., 2013. Biofloc Production Systems for Aquaculture. Southern Regional Aquaculture Center, SRAC, 1-11. 
Hargreaves, J., 2006. Photosynthetic Suspended Growth System in Aquaculture. Aquacultural Engineering, 344-363.

Jiang, S., 2010. Aquaculture, Capture Fisheries, and Wild Fish Stocks. Resource and Energy Economics, 65-77.

Ju, Z., Forster, I., Conquest, L., Dominy, W., Kuo, W., \& Horgen, F., 2008a. Determination of Microbial Community Strutures of Shrimp Floc Culture by Biomarkers and Analysis of Floc Amino Acid Profiles. Aquaculture Research, 118-133.

Ju, Z., Forster, I., Conquest, L., \& Dominy, W., 2008 b. Enhanced Growth Effects on Shrimp (Litopenaeus vannamei) From Inclusion of Whole Shrimp Floc or Floc Fractions to a Formulated Diet. Aquaculture Nutrition, 533-543.

Lara, G., Krummenauer, D., Abreu, P., Poersch, L., \& Wasielesky, W., 2016. The Use of Different Aerators on Litopenaeus vannamei Biofloc Culture System: Effects on Water Quality, Shrimp Growth and Biofloc Composition. Aquaculture International, 1-16.

Liang, W., Luo, G., Tan, H., Ma, N., Zhang, N., \& Li, L., 2014. Efficiency of Biofloc Technology in Suspended Growth Reactors Treating Aquacultural Solid Under Intermittent Aeration. Aquacultural Engineering, 41-47.

Little, D., Murray, F., Azim, E., Leschen, W., Boyd, K., Watterson, A., \& Young, J., 2008. Option for Producing a Warm Water Fish in the UK: Limit to "Green Growth" Trends in Food Science and Technology, 255-264.

Liu, L., Hu, Z., Dai, X., \& Avnimelech, Y., 2014. Effects of Addition of Maize Starch on the Yield, Water Quality and Formation of Bioflocs in an Integrated Shrimp Culture System. Aquaculture, 7986.

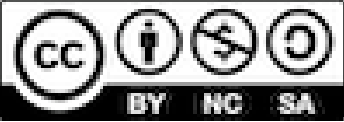

Liu, W., Luo, G., Tan, H., \& Sun, D., 2016. Effects of Sludge Retention Time on Water Quality and Bioflocs Yield, Nutritional Composition, Apparent Digestibility Coefficients Treating Recirculating Aquaculture System Effluent in Sequencing Batch Reactor. Aquacultural Engineering, 58-64.

Long, L., Yang, J., Li, Y., Guan, C., \& Wu, F., 2015. Effect of Biofloc Technology on Growth, Digestive Enzyme Activity, Hematology, and Immune Response of Genetically Improved Farmed Tilapia (Oreochromis niloticus). Aquaculture, 135-141.

Luo, G., Avnimelech, Y., Pan, Y., \& Tan, H., 2013. Inorganic Nitrogen Dynamics in Sequencing Batch Reactors Using Biofloc Technology to Treat Aquaculture Sludge. Aquacultural Engineering, 7379.

Luo, G., Gao, Q., Wang, C., Liu, W., Sun, D., Li, L., \& Tan, H., 2014. Growth, Digestive Activity, Welfare, and Partial Cost-effectiveness of Genetically Improved Farmed Tilapia (Oreochromis Niloticus) Cultured in a Recirculating Aquaculture System and an Indoor Biofloc System. Aquaculture, 1-7.

Martínez, L., Emerenciano, M., Miranda, A., \& Martínez, M., 2014. Microbial-based Systems for Aquaculture of Fish and Shrimp: an Updated Review. Aquaculture, 1-18.

Monroy, M., De Lara, R., Castro, J., Castro, G., \& Emerenciano, M., 2013. Composición y Abundancia de Comunidades Microbianas Asociados al Biofloc en un Cultivo de Tilapia. Revista de Biología Marina y Oceanografía, 511-520.

Moriarty, D., 1997. The Role of Microorganisms in Aquaculture Ponds. Aquaculture, 333-349.

Munguia, P., Alatorre, O., Rico, E., Torres, I., Cruz, A., Ocampo, R., García, J., \& Guevara, R., 2015. Perspective for Aquaponic Systems: (Omic) Technologies for Microbial Community Analysis. BioMed Research International, 1-2. 
Nahar, A., Abu Bakar Siddik, M., Chaklader, R., Hanif, A., Sharker, R., \& Rahman, M., 2015. Biofloc Technology in Aquaculture Systems Generates Higher Income in Mono-sex Nile Tilapia Farming in Bangladesh. Advances in Biological Research, 236241.

Ogello, E., Musa, S., Mulanda, C., Abwao, J., \& Mbonge, J., 2014. An Appraisal of the Feasibility of Tilapia Production in Ponds Using Biofloc Technology: A review. International Journal of Aquatic Science, 21-39.

Prajith, K., 2012. Application of Biofloc Technology (BFT) in the Nursery Rearing and Farming of Giant Freshwater Prawn, Macrobrachium Rosenbergii (deMan), Cochin University of Science and Technology.

Pérez, A., Pérez, C., \& Hernández, M., 2013. Pondreared Malaysian Prawn Macrobrachium Rosenbergii with the Biofloc System. Aquaculture, 105-110.

Rahman, M. M., Nagelkerke, L., Verdegem, M., Wahab, A., \& Verreth, J., 2008. Relationships Among Water Quality, Food Resources, Fish Diet and Fish Growth in Polyculture Ponds: A Multivariate Approach. Aquaculture, 108-115.

Ray, A., 2012. Biofloc Technology For Superintensive Shrimp Culture. In Y. Avnimelech, Biofloc Technology - A Practical Guide Book, 2d Edition, The World Aquaculture Society, Louisiana, 4-28.

Ray, A., \& Lotz, J., 2014. Comparing a Chemoautotrophic-based Biofloc System and Three Heterotrophic-based Systems Receiving Different Carbohydrate Sources. Aquacultural Engineering, 5461.

Ray, A., Dillon, K., \& Lotz, J., 2011. Water Quality Dynamics and Shrimp (Litopenaeus vannamei) Production in Intensive, Mesohaline Culture Systems with two Levels of Biofloc Management. Aquacultural Engineering, 127-136.

Ray, A., Seaborn, G., Leffler, J., \& Browdy, C., 2010. Characterization of Microbial Communities in Minimal-exchange, Intensive Aquaculture Systems and the Effects of Suspended Solids Management. Aquaculture, 130-138.

Schrader, K., Green, B., \& Perschbacher, P., 2011. Development of Phytoplankton Communities and Common Off-flavors in a Biofloc Technology System Used for the Culture of Channel Catfish (Ictalurus punctatus). Aquacultural Engineering, 118-126.

Vásquez, R., Pupo, A., \& Jiménez, H., 2014. Sistema Energéticamente Eficiente y de Bajo Costo para Controlar la Temperatura y Aumentar el Oxígeno en Estanques de Cultivo de Alevines de Tilapia Roja. Facultad de Ingeniería, 9-23.

Wang, C., Chang, C., Chien, Y., \& Lai, H., 2015a. The Performance of Coupling Membrane Filtration in Recirculating Aquaponic System for Tilapia Culture. International Biodeterioration \& Biodegradation, 107, 21-30.

Wang, G., Yu, E., Xie, J., Yu, D., Li, Z., Luo, W., Qiu, L., \& Zheng, Z., 2015b. Effect of C/N Ratio on Water Quality in Zero-water Exchange Tanks and the Biofloc Supplementation in Feed on the Growth Performance of Crucian Carp, Carassius auratus. Aquaculture, 98104.

Widanarni, Ekasari, J., \& Maryam, S., 2012. Evaluation of Biofloc Technology Application on Water Quality and Production Performance of Red Tilapia Oreochromis sp. Cultured at Different Stocking Densities. HAYATI J Biosci, 73-80.

Wu, L., Peng, C., Peng, Y., \& Ma, Y., 2012. Effect of Wastewater COD/N Ratio on Aerobic Nitrifying Sludge Granulation and Microbial Population Shift. Journal of Environmental Sciences, 234-241. 
Xu, W., Morris, T., \& Samocha, T., 2016. Effects of C/N Ratio on Biofloc Development, Water Quality, and Performance of Litopenaeus vannamei Juveniles in a Biofloc-based, High-density, Zero-exchange, Outdoor Tank System. Aquaculture, 169-175.

Yong, P., 2014. Biofloc Technology in Shrimp Farming: Success and Failure. Aquaculture, 13-16.

Zhao, P., Huang, J., Wang, X., Song, X., Yang, C., Zhang, X., \& Wang, G., 2012. The Application of Bioflocs Technology in High-intensive, Zero Exchange Farming Systems of Marsupenaeus Japonicus. Aquaculture, 97-106. 